\title{
Biosorption of lead(II) and chromium(VI) on groundnut hull: Equilibrium, kinetics and thermodynamics study
}

\author{
Suleman Qaiser* \\ Department of Chemical Engineering \\ University of Engineering and Technology \\ Lahore, Pakistan \\ E-mail: engrsqaiser@yahoo.com \\ Anwar R. Saleemi \\ Department of Chemical Engineering \\ University of Engineering and Technology \\ Lahore, Pakistan \\ Muhammad Umar \\ Department of Chemical Engineering \\ University of Engineering and Technology \\ Lahore, Pakistan
}

Financial support: Merit scholarship for PhD to Suleman Qaiser by Higher Education Commission Pakistan.

Keywords: biosorption, equilibrium, groundnut hull, kinetics, thermodynamics.

Abbreviations: FTIR: Fourier transform infrared

rpm: rotations per minute

SEM: scanning electron microscope

The biosorption of lead(II) and chromium(VI) on groundnut hull was investigated. Batch biosorption experiments were conducted to find the equilibrium time and biosorption capacity. Effect of parameters like pH, temperature and initial metal concentration was studied. The maximum biosorption capacity of lead(II) and chromium(VI) was found to be $31.54 \pm 0.63$ and $30.21 \pm 0.74 \mathrm{mg} \mathrm{g}^{-1}$, respectively. The optimum $\mathrm{pH}$ for lead(II) and chromium(VI) removal was $5 \pm 0.1$ and $2 \pm$ 0.1 , respectively. The temperature change, in the range of $20-45^{\circ} \mathrm{C}$ affected the biosorption capacity. The maximum removal of lead(II) was achieved at $20 \pm 2^{\circ} \mathrm{C}$, where as maximum uptake of chromium(VI) was observed at $40 \pm 2^{\circ} \mathrm{C}$. The biosorption data was fitted to the Langmuir and the Freundlich isotherm models. The Langmuir model showed better representation of data, with correlation coefficient greater than 0.98 . The kinetics of biosorption followed the pseudo second order kinetics model. The thermodynamics parameters were evaluated from the experimental data.

Lead and chromium are the major toxic pollutants, which entered the water streams through various industrial operations. The potential sources of chromium(VI) wastes are effluents from metallurgy, electroplating, leather tanning, textile dyeing, paint, ink, and aluminium manufacturing industries (Bhattacharyya and Gupta, 2006; Verma et al. 2006). Lead is used as industrial raw material in the manufacture of storage batteries, pigments, leaded glass, fuels, photographic materials, solder and steel products (Nadeem et al. 2006). Lead and chromium are toxic contaminants, even in very low concentrations. Severe lead poisoning can cause encephalopathy, with permanent damage, while moderate lead poisoning result in neurobehavioral and intelligent deficit (Chen et al. 2007). The presence of lead in drinking water, even in low concentrations may cause anaemia, hepatitis and nephritic syndrome (Zulkali et al. 2006). Lead poisoning in humans causes severe damage to kidney, nervous system, reproductive system, liver and brain (Ozer, 2007). Chromium (VI) is carcinogenic to both humans and animals (Mungasavalli et al. 2007). Strong exposure of chromium (VI) causes cancer in the digestive tract and lungs and may cause gastric pain, nausea, vomiting, severe diarrhea, and hemorrhage (Mohanty et al. 2005). According to the United States Environmental Protection Agency (USEPA) the maximum permissible limits in wastewater and potable water are $0.1 \mathrm{mg} \mathrm{l}^{-1}$ and $0.015 \mathrm{mg} \mathrm{l}^{-1}$ for lead(II) and $1.0 \mathrm{mg}$ $\mathrm{l}^{-1}$ and $0.05 \mathrm{mg} \mathrm{l}^{-1}$ for chromium(VI), respectively (Park et al. 2005).

The conventional methods for treatment of lead (II) and chromium (VI) wastes include: precipitation, adsorption with activated carbon, ion exchange, membrane processes, oxidation and reduction (Wang et al. 2003). These methods are expensive and often generate chemical sludge, whose

*Corresponding author 
disposal is problematic.

The biosorption is a process that utilizes low-cost biosorbents to sequester toxic heavy metals (Kratochvil and Volesky, 1998). Biosorption has distinct advantages over the conventional methods which include: reusability of biomaterial, low operating cost, selectivity for specific metal, short operation time and no chemical sludge (Mungasavalli et al. 2007). In the recent years many biosorbents materials of agricultural based have been utilized for heavy metal biosorption. These include: coconut husk and shell (Tan et al. 1993; Amuda et al. 2007), sea weeds (Senthilkumar et al. 2007), bagasse ash (Gupta et al. 1998), hazelnut shell (Cimino et al. 2000; Bulut and Tez, 2007), peanut hull (Brown et al. 2000), tree fern (Ho, 2005), black gram husk (Saeed et al. 2005), maize leaf (Babarinde et al. 2006), maize, sun flower waste (Zhang and Banks, 2006), coffee beans (Kaikake et al. 2007), Ficus religiosa leaves (Qaiser et al. 2007; Qaiser et al. 2009), wheat bran (Ozer, 2007), almond shell (Bulut and Tez, 2007), tea waste (Amarasinghe and Williams, 2007).

Groundnut hull is an agricultural based waste material and these materials as discussed previously have the potential to sequester metals from solutions. The activated carbon prepared from groundnut shell has been utilized for the sorption of dyes methylene blue (Kannan and Sundaram, 2001) and malachite green (Malik et al. 2007). No report on the utilization of groundnut hull, for biosorption of lead(II) and chromium(VI) has been found in literature. The present research was conducted to utilize groundnut hull for the biosorption of lead(II) and chromium(VI) from wastewater. Influence of operating conditions like temperature, $\mathrm{pH}$, biosorbent dose and initial metal concentrations on biosorption process were investigated. The equilibrium, kinetics and thermodynamics of biosorption process were studied.

\section{MATERIALS AND METHODS}

\section{Chemicals and instruments}

Experiments were performed in triplicate and average values were used in the results. Chemicals used were of analytical reagent grade. The stock lead(II) and chromium(VI) solutions of $1000 \mathrm{mg} \mathrm{l}^{-1}$ concentrations were prepared by dissolving, $1.6 \mathrm{~g}$ lead nitrate (Merck Germany) and $2.827 \mathrm{~g}$ potassium dichromate (Fischer Germany), respectively in one litre of distilled water. The stock solutions were further diluted to obtain, solutions of various known concentrations of lead(II) and chromium(VI). A variable speed shaker 20-500 rpm was used for batch experimentation. It has the capacity of holding eight Erlenmeyer flasks, simultaneously. It was equipped with thermostatically controlled, heating water bath. Initial concentrations of lead(II) and chromium(VI) solutions, used in the experiments were $100 \mathrm{mg} \mathrm{l}^{-1}$. The rotational speed of stirrer, in all the experiments was kept constant at $200 \mathrm{rpm}$. Except for the experiments to study the effect of dose, $0.5 \mathrm{~g}$ biosorbent was used in $100 \mathrm{ml}$ of solution. After completion of each batch, the solution was filtered. The filtrate was analyzed, using Shimadzu 6800 Atomic Absorption Spectrophotometer, to determine the quantity of residual metals. The quantity of sorbed metal was found by material balance. The metal uptake, $\mathrm{q}_{\mathrm{t}}$ was determined using the following equation:

$$
\mathrm{q}_{\mathrm{t}}=\mathrm{V}\left(\mathrm{C}_{\mathrm{o}}-\mathrm{C}_{\mathrm{f}}\right) / \mathrm{m}
$$

Where, $\mathrm{C}_{\mathrm{o}}$ and $\mathrm{C}_{\mathrm{f}}$ are the initial and final concentration of metal in solution ( $\mathrm{mg} \mathrm{l}^{-1}$ ), $\mathrm{V}$ is the volume of solution (l) and $\mathrm{m}$ is the mass of biosorbent $(\mathrm{g})$.

\section{Preparation of biosorbent}

The Groundnut hull was collected locally and washed with

Table 1. Elemental analysis and surface area characterization of biosorbent.

\begin{tabular}{|c|c|c|c|c|c|c|}
\hline \multicolumn{7}{|c|}{ Elemental analysis of Groundnut hull } \\
\hline Element & C & $\mathrm{H}$ & $\mathrm{N}$ & $\mathrm{O}$ & & \\
\hline$\%$ age & 45.5 & 6.7 & 0.9 & 33.9 & & \\
\hline Element & $\mathrm{Ca}$ & $\mathrm{Fe}$ & $\mathrm{Mg}$ & $\mathrm{Mn}$ & $\mathrm{Na}$ & $\mathrm{K}$ \\
\hline$\%$ age & 0.28 & 0.001 & 0.009 & 0.002 & 0.024 & 0.019 \\
\hline \multicolumn{7}{|c|}{ Surface are and pore size analysis Groundnut hull } \\
\hline BET surface & \multicolumn{3}{|c|}{ Langmuir surface } & \multicolumn{2}{|l|}{ Pore volume } & Pore diameter \\
\hline area $\left(m^{2} g^{-1}\right)$ & \multicolumn{3}{|c|}{ area $\left(m^{2} g^{-1}\right)$} & \multicolumn{2}{|l|}{$\left(\mathrm{cm}^{3} \mathrm{~g}^{-1}\right)$} & $\AA$ \\
\hline 3.85 & \multicolumn{3}{|c|}{24.75} & \multicolumn{2}{|l|}{0.07} & 120.61 \\
\hline
\end{tabular}


Table 2. The Langmuir model, Freundlich model, Lagergren first order, pseudo second order model and thermodynamics parameters for lead(II) and chromium(VI) biosorption.

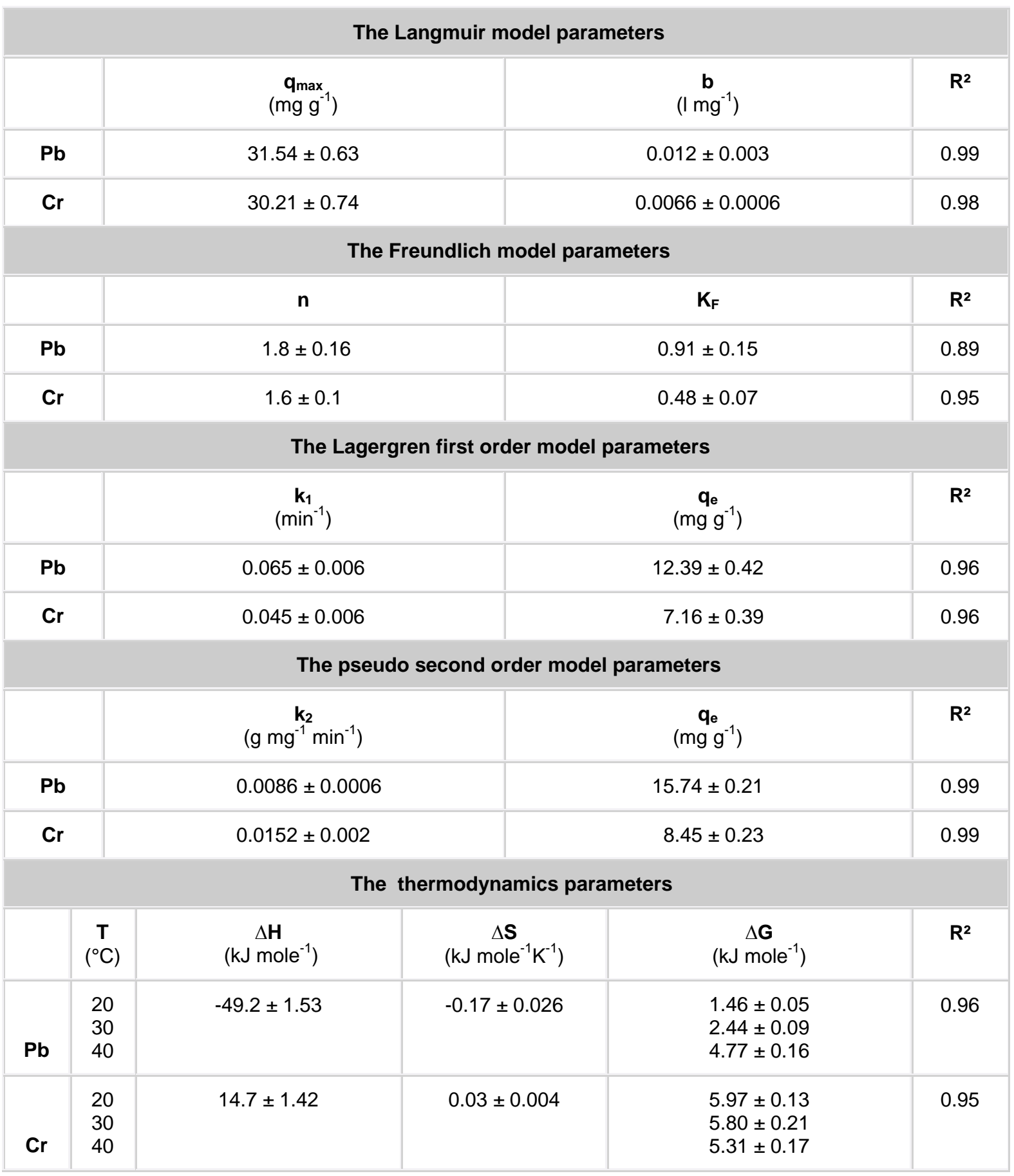

tap water to remove, the attached dust and other impurities. The washed groundnut hull was ground in a mechanical grinder to form a powder. The powder was sieved and a size fraction in the range of $200-300 \mu \mathrm{m}$ was used in all the experiments. This powder was soaked $(20 \mathrm{~g} / \mathrm{l})$ in $0.1 \mathrm{M}$ nitric acid for 24 hrs. The mixture was filtered and the powder residue was washed with distilled water, several times to remove any acid contents. This filtered biomass was first dried, at room temperature and then in an oven at $105^{\circ} \mathrm{C}$ for $6-8 \mathrm{hrs}$. The dried biomass was stored in air tight glass bottles to protect it from moisture.

\section{Characterization of biosorbent}

The Fourier Transform Infrared (FTIR) spectroscopy was used to identify the functional groups present in the 
biomass. The biomass samples were examined, using JASCO FTIR spectrometer, within range of $400-4000 \mathrm{~cm}^{-1}$. All analysis were performed using, $\mathrm{KBr}$ as back ground material. In order to form pellets, $0.002 \mathrm{~g}$ of groundnut hull was mixed with $0.3 \mathrm{~g} \mathrm{KBr}$ and pressed at 6-8 bar pressure. The surface structure and particle size distribution of biosorbent was examined using Hitachi Scanning Electron Microscope (SEM). The samples were covered, with a thin layer of gold and an electron acceleration voltage of $20 \mathrm{kV}$ was applied. The surface area, pore volume and pore size measurements of biosorbent was carried out using, Quantachrome NOVA 2200C USA, surface area and pore size analyzer. The gas mixture of 22.9 mole \% nitrogen and 77.1 mole \% helium was used for this purpose. The elemental analysis of the biosorbent was performed using, Costech Instrument 4010 elemental analyzer, Thermo Jarrel Ash (IRIS, USA) inductively couple plasma atomic emission spectrometer (ICP-AES) and Shimazdu atomic absorption spectrometer.

\section{RESULTS AND DISCUSSION}

\section{Characterization of biosorben}

The FTIR spectra of groundnut hull is shown in Figure 1. Broad peak at $3400 \mathrm{~cm}^{-1}$ is the indicator of $-\mathrm{OH}$ and $-\mathrm{NH}$ groups. The stretching of the -OH groups bound to methyl radicals presented a signal between 2950 and $2887 \mathrm{~cm}^{-1}$. The peaks located at 1737 and $1633 \mathrm{~cm}^{-1}$ are characteristics of carbonyl group stretching from aldehydes and ketones. The presence of -OH group, along with carbonyl group, confirms the presence of carboxylic acid groups in the biosorbent. The peaks at $1508 \mathrm{~cm}^{-1}$ are associated with the stretching in aromatic rings. The peaks observed at 1071 and $1024 \mathrm{~cm}^{-1}$ are due to $\mathrm{C}-\mathrm{H}$ and $\mathrm{C}-\mathrm{O}$ bonds. The $-\mathrm{OH}$, $\mathrm{NH}$, carbonyl and carboxylic groups are important sorption sites (Volesky, 2003). The FTIR spectra of the Groundnut hull, attained after biosorption of lead(II) and chromium(VI) is shown in Figure 2 and Figure 3. As compared to simple groundnut hull, the broadening of $-\mathrm{OH}$ peak at $3400 \mathrm{~cm}^{-1}$ and carbonyl group peak at $1633 \mathrm{~cm}^{-1}$ was observed. This indicates the involvement of hydroxyl and carbonyl groups in the biosorption of lead(II) and chromium(VI).

The SEM micrographs of groundnut hull are shown in Figure 4. These micrographs represent a porous structure, with large surface area. The results of surface area analysis further confirmed the porous nature and high surface area of the biosorbent. The surface area, pore volume, pore dia. and elemental analysis of the biosorbent are presented in Table 1 . The elemental analysis of the biosorbent indicates the presence of $\mathrm{Ca}, \mathrm{Mg}, \mathrm{Na}$ and $\mathrm{K}$. These light metals can be exchanged with heavy metals in an ion exchange reaction. The involvement of these metals in biosorption was confirmed by analyzing the final solution for light metals.

\section{Determination of equilibrium time}

The variation in metal uptake, with time is shown in Figure 5. As can be seen from this Figure, the biosorption process took place in two stages. The first stage was rapid, where about $75 \%$ biosorption was completed, within first 15 min. The second stage represented a slower progressive biosorption. The rapid initial biosorption may be attributed to the accumulation of metals on to the surface of biosorbent, due to its large surface area. With the progressive occupation of these sites, process became slower in the second stage. Moreover the initially deposited metal ions penetrate to the interior of the biosorbent through intra-particle diffusion which was slower process. This is in accordance with the observations of other similar studies (Sangi et al. 2008; Qaiser et al. 2009). The biosorption process attained equilibrium in $1 \mathrm{hr}$. Based on the results of kinetics experiments, a time of $1 \mathrm{hr}$ was considered to be adequate for remaining experimentations. The release of calcium, magnesium, sodium and potassium ions was also observed as result of lead(II) binding to groundnut hull. The elemental analysis shown in Table 1 indicated the presence of these light metals in the groundnut hull. The release of light metals as result of lead(II) biosorption to groundnut hull is shown in Figure 6 . The release of these light metal ions revealed that ion exchange was taking place between the lead(II) and light metals. Moreover decrease in solution $\mathrm{pH}$, in case of lead(II) biosorption was observed. This may be due to the release of $\mathrm{H}^{+}$ions, as result of lead(II) attachment to the biosorbent. On the other hand, an increase in solution $\mathrm{pH}$ was observed as result of chromium(VI) biosorption. This was probably due to the release of $\mathrm{OH}^{-}$ions, in exchange with $\mathrm{HCrO}_{4}^{-}$ions. These results clearly indicate that ion exchange was the major removal mechanism in the metal biosorption.

\section{Effect of biosorbent dose}

The removal efficiency and specific uptake of metals depend on type and quantity of the biosorbent. If no information is available, for particular type of biomass it is better to find the optimal dose, experimentally. The quantity of biosorbent was varied from 1-50 $\mathrm{g} \mathrm{l}^{-1}$. As revealed in Figure 7, the percentage removal increased with increase in biosorbent dose. There was negligible increase in the percentage removal, beyond the dose of $20 \mathrm{~g} \mathrm{l}^{-1}$. Considering these results, a dose of $5 \mathrm{~g} \mathrm{l}^{-1}$ was considered sufficient, for the optimal removal of both metals. Moreover, the biosorption capacity was high at low dose rates. The reason for this may be the availability of lesser binding sites and these were fully utilized.

\section{Effect of pH}

In heavy metal biosorption, $\mathrm{pH}$ is the most important parameter. The speciation of metals in the solution is $\mathrm{pH}$ dependent. At the same time, the state of chemically active sites is changed by the solution $\mathrm{pH}$. The solution $\mathrm{pH}$ was 
varied in the range from 1-6, by using $0.1 \mathrm{M}$ nitric acid and $0.1 \mathrm{M}$ ammonia as buffers. As shown in Figure 8, maximum removal of chromium(VI) was achieved at $\mathrm{pH} 2$ \pm 0.1 , where as lead(II) has an optimal $\mathrm{pH}$ of $5 \pm 0.1$. At $\mathrm{pH}$ higher than 6 for both metals precipitation occurred, due to this reason biosorption was not studied beyond $\mathrm{pH}$ of 6 . The FTIR spectra of groundnut hull indicated the presence of hydroxyl, amino, carboxylic and carbonyl groups. These groups are positively charged, when protonated at low $\mathrm{pH}$ and are negatively charged at higher $\mathrm{pH}$. So at low $\mathrm{pH}$, the attachment of lead(II) to sorption sites of groundnut hull was restricted. Thus removal of lead(II) was repressed at low $\mathrm{pH}$. With the increase in $\mathrm{pH}$, there was an increase in ligands with negative charges, which resulted in increased binding of lead(II). However, at $\mathrm{pH} \mathrm{6}$, the lead uptake decreased due to its partial precipitation. At low $\mathrm{pH}$, dominant form of chromium(VI) is $\mathrm{HCrO}_{4}^{-}$(Cimino et al. 2000) which was attracted by positively charged sites. The further justification, for higher removal of chromium at low $\mathrm{pH}$ is the reduction of chromium(VI) to chromium(III) (Park et al. 2005; Qaiser et al. 2007), which was then biosorbed by the sorbent. As a result of this reduction reaction, $\mathrm{H}^{+}$was consumed and an increase in $\mathrm{pH}$ was observed at the end of experiments. The reduction of $\mathrm{Cr}(\mathrm{VI})$ to $\mathrm{Cr}(\mathrm{III})$ was further confirmed by analyzing the solution for $\mathrm{Cr}(\mathrm{VI})$ using 1,5 diphenylcarbazide in spectrophotometer.

\section{Biosorption equilibrium}

The biosorption equilibrium is established, when the concentration of sorbate in bulk solution is in dynamic balance with that on the liquid-sorbent interface. The degree of the sorbent affinity for the sorbate determines its distribution between the solid and liquid phases. Several models are often employed to interpret the equilibrium data. In the present research, the Langmuir and the Freundlich models were utilized to explain the experimental data.

The Langmuir model (Langmuir, 1918) is based on the hypothesis that uptake occurs on a homogenous surface by monolayer sorption without interaction between adsorbed molecules. It is expressed as:

$$
\mathrm{q}_{\mathrm{e}}=\mathrm{q}_{\max } \mathrm{b} \mathrm{C}_{\mathrm{e}} / 1+\mathrm{bC}_{\mathrm{e}}
$$

Equation (2) can be written in linear form as:

$$
\mathrm{C}_{\mathrm{e}} / \mathrm{q}_{\mathrm{e}}=\mathrm{C}_{\mathrm{e}} / \mathrm{q}_{\max }+1 / \mathrm{q}_{\max } \mathrm{b}
$$

Where, $\mathrm{q}_{\max }$ represents the maximum biosorption capacity and $b$ is an affinity parameter, related to the energy of biosorption.

The Freundlich model (Freundlich, 1928) proposes a monolayer sorption with heterogeneous energetic distribution of active sites and with interaction between adsorbed molecules. It is expressed mathematically as:

$$
\mathrm{q}_{\mathrm{e}}=\mathrm{K}_{\mathrm{F}}\left(\mathrm{C}_{\mathrm{e}}\right)^{1 / \mathrm{n}}
$$

Equation [4] can be written in linear form as:

$$
\ln \mathrm{q}_{\mathrm{e}}=1 / \mathrm{n} \ln \mathrm{C}_{\mathrm{e}}+\ln \mathrm{K}_{\mathrm{F}}
$$

Where; $\mathrm{K}_{\mathrm{F}}$ and $\mathrm{n}$ are the Freundlich coefficients. The constant $\mathrm{K}_{\mathrm{F}}$ provides an indication of the biosorption capacity of biosorbent and $\mathrm{n}$ is related to the intensity of biosorption.

Initial concentration of both metals was varied from 10 to $1000 \mathrm{mg} \mathrm{l}^{-1}$ and quantity of biosorbent was kept constant at 0.5 g. Equilibrium concentration, $\mathrm{C}_{\mathrm{e}}$ and equilibrium capacity, $\mathrm{q}_{\mathrm{e}}$ were determined. $\mathrm{C}_{\mathrm{e}}$ was plotted against $\mathrm{C}_{\mathrm{e}} / \mathrm{q}_{\mathrm{e}}$ and straight lines as revealed in Figure 9 were fitted by regression.

In order to see the applicability of Freundlich model, $\ln \mathrm{C}_{\mathrm{e}}$ was plotted against $\ln \mathrm{q}_{\mathrm{e}}$ and straight lines as shown in Figure 10 were fitted to the plots. The values of the Langmuir and the Freundlich model parameters were evaluated from the slope and intercept of lines in Figure 9 and Figure 10 and are presented in Table 2. The experimentally determined equilibrium isotherms, for both metals were compared with the theoretical Langmuir and Freundlich isotherms. This comparison is shown in Figure 11, which depicts that the Langmuir model gave better representation of the experimental data.

\section{Biosorption kinetics}

In order to investigate the biosorption kinetics, the Lagergren first order (Lagergren, 1898) and pseudo second order kinetics models (Ho and Mckay, 1999) were applied. The pseudo second order model represented the data more appropriately, with correlation coefficient greater than 0.99 .

The expression for the Lagergren first order model is:

$$
\mathrm{dq}_{\mathrm{t}} / \mathrm{dt}=\mathrm{k}_{1}\left(\mathrm{q}_{\mathrm{e}}-\mathrm{q}_{\mathrm{t}}\right)
$$

This equation [6] can be integrated to yield a linearized form as

$$
\log \left(\mathrm{q}_{\mathrm{e}}-\mathrm{q}_{\mathrm{t}}\right)=\log \mathrm{q}_{\mathrm{e}}-\mathrm{k}_{1} \mathrm{t} / 2.303
$$

Where, $\mathrm{k}_{1}$ is the Lagergren rate constant for adsorption (min. $\left.^{-1}\right), q_{\mathrm{e}}$ is the amount of metal biosorbed at equilibrium $\left(\mathrm{mg} \mathrm{g}^{-1}\right)$ and $\mathrm{q}_{\mathrm{t}}$ is the amount of metal biosorbed $\left(\mathrm{mg} \mathrm{g}^{-1}\right)$ at any time t.

Time, $\mathrm{t}$ was plotted against $\log \left(\mathrm{q}_{\mathrm{e}}-\mathrm{q}_{\mathrm{t}}\right)$ and straight lines, shown in Figure 12 were fitted by regression. The values of $\mathrm{k}_{1}$ and $\mathrm{q}_{\mathrm{e}}$ were determined from the slope and intercept of lines in Figure 12 and are presented in Table 2.

The equation of pseudo second order model is:

$$
\mathrm{dq}_{\mathrm{t}} / \mathrm{dt}=\mathrm{k}_{2}\left(\mathrm{q}_{\mathrm{e}}-\mathrm{q}_{\mathrm{t}}\right)^{2}
$$


Integration and rearrangement of equation [8] yielded the following equation

$$
\mathrm{t} / \mathrm{q}_{\mathrm{t}}=1 / \mathrm{k}_{2} \mathrm{q}_{\mathrm{e}}^{2}+1 / \mathrm{q}_{\mathrm{e}} \mathrm{t}
$$

Where, $k_{2}$ is equilibrium rate constant of second order kinetics model $\left(\mathrm{g} \mathrm{mg}^{-1} \mathrm{~min}^{-1}\right), \mathrm{q}_{\mathrm{e}}$ is the equilibrium capacity and $\mathrm{q}_{\mathrm{t}}$ is the biosorption capacity at any time $\mathrm{t}$. The time, $\mathrm{t}$ was plotted against $\mathrm{t} / \mathrm{q}_{\mathrm{t}}$ and straight lines as shown in Figure 13 were fitted to these plots. The correlation coefficients of 0.99 indicated the applicability of pseudo second order model to the present system. The applicability of this model suggested that biosorption of lead(II) and chromium(VI), on groundnut hull was based on chemical reaction, between metals and active sites of the biosorbent. The elemental analysis and FTIR spectra of groundnut hull also supported this argument. The equilibrium rate constant, $\mathrm{k}_{2}$ and equilibrium capacity, $\mathrm{q}_{\mathrm{e}}$ were determined from the slope and intercept of the lines in Figure 13. The pseudo second order model parameters are listed in Table 2 . The values of the equilibrium capacity evaluated from the pseudo second order model were in close agreement to those determined experimentally. The comparison of experimental data and the pseudo second order model is shown in Figure 5. This comparison revealed that model gave a good fit of the experimental data points.

\section{Effect of temperature}

The effect of temperature on biosorption of lead(II) and chromium(VI), was studied by varying the temperature in the range $20-45^{\circ} \mathrm{C}$. As depicted by Figure 14 , the change in temperature effected the biosorption of lead(II) and chromium(VI) differently. The biosorption of lead(II) decreased with increasing temperature from $20-45^{\circ} \mathrm{C}$, while that of chromium(VI) increased with increasing temperature up to $40^{\circ} \mathrm{C}$ and then started decreasing. The temperature higher than $40^{\circ} \mathrm{C}$ caused a change, in the texture of the biomass and thus reduced its biosorption capacity. The reason for having different behaviour of lead(II) and chromium(VI) biosorption with temperature may be due to the different mechanisms involved in the biosorption of these metals. The biosorbent contains more than one type of sites for metal binding. The effect of temperature on each site is different and contributes to overall metal uptake.

The effect of temperature on biosorption depends on the enthalpy change. The biosorption equilibrium constant, $\mathrm{k}_{\mathrm{d}}$ is described thermodynamically by Van't Hoff equation as (Verma et al. 2006; Senthilkumar et al. 2007).

$\ln \mathrm{k}_{\mathrm{d}}=-\Delta \mathrm{H} / \mathrm{RT}+\Delta \mathrm{S} / \mathrm{R}$

The values of Gibbs free energy can be calculated by using the following equation.

$\Delta \mathrm{G}=-\mathrm{RT} \ln \mathrm{k}_{\mathrm{d}}$

Where, $\Delta \mathrm{H}, \Delta \mathrm{S}$ and $\Delta \mathrm{G}$ are the change in enthalpy, entropy and Gibbs free energy of the system, respectively. $\mathrm{T}$ is the absolute temperature $(\mathrm{K}), \mathrm{R}$ is the gas constant $(8.314 \mathrm{~J}$

Table 3. Comparison of maximum sorption capacity of Groundnut hull with other sorbents.

\begin{tabular}{|c|c|c|c|}
\hline Biosorbent & $\begin{array}{c}q_{\max } P b(I I) \\
\left(\mathrm{mg} \mathrm{g}^{-1}\right)\end{array}$ & $\begin{array}{c}q_{\max } \operatorname{Cr}(\mathrm{VI}) \\
\left(\mathrm{mg} \mathrm{g}^{-1}\right)\end{array}$ & Reference \\
\hline Ficus religiosa leaves & 37.45 & 26.25 & Qaiser et al. 2007 \\
\hline Caulerpa lentillifera & 29.0 & - & Apiratikul and Pavasant, 2008 \\
\hline bagasse fly ash & 2.5 & 4.35 & Gupta and Ali, 2004 \\
\hline Coir & 18.9 & - & Conrad and Hansen, 2007 \\
\hline Aspergilus niger & 10.1 & - & Kapoor et al. 1999 \\
\hline Coconut shell charcoal & - & 4.05 & Babel and Kurniawan, 2004 \\
\hline Coconut husk fibers & - & 29.0 & Tan et al. 1993 \\
\hline sugar beat pulp & - & 17.2 & Sharma and Forster, 1994 \\
\hline Maize cob & - & 13.8 & Sharma and Forster, 1994 \\
\hline sugar cane bagasse & - & 13.4 & Sharma and Forster, 1994 \\
\hline Groundnut hull & 31.54 & 30.21 & Qaiser et al. 2009 (As published) \\
\hline
\end{tabular}


mole $\mathrm{K}^{-1}$ ) and $\mathrm{k}_{\mathrm{d}}$ is the equilibrium constant given by the following equation (Bektas et al. 2004).

$\mathrm{k}_{\mathrm{d}}=\mathrm{q}_{\mathrm{e}} / \mathrm{C}_{\mathrm{e}}$

Values of $\mathrm{k}_{\mathrm{d}}\left(\mathrm{lg}^{-1}\right)$ were calculated at different temperatures using the Equation 12. The plot of reciprocal temperature $(1000 / T)$ versus $\ln k_{d}$ yielded straight lines, as shown in Figure 15, with correlation coefficient 0.96 for lead(II) and 0.95 for chromium(VI). The values of $\Delta \mathrm{H}$ and $\Delta \mathrm{S}$ were determined from the slope and intercept of lines in Figure 15. The values of $\Delta G$ at different temperatures were calculated using Equation 11. The values of $\Delta \mathrm{H}, \Delta \mathrm{S}$ and $\Delta \mathrm{G}$ are listed in Table 2.

Positive values of $\Delta \mathrm{H}, \Delta \mathrm{G}$ and higher removal capacities at elevated temperatures, indicated that biosorption of chromium(VI) was endothermic in nature. At higher temperatures the energy of system seemed to facilitate the chromium(VI) attachments onto biosorbent surfaces. On the other hand enthalpy change for lead(II) was negative and a decrease in removal capacity was observed with increase in temperature from $20^{\circ} \mathrm{C}$ to $45^{\circ} \mathrm{C}$. This showed that biosorption of lead(II) was exothermic.

\section{Comparison of groundnut hull with other sorbents}

Table 3 summaries the comparison of the maximum biosorption capacities of various sorbents including groundnut hull, for lead(II) and chromium(VI). This comparison showed that groundnut hull has higher biosorption capacities than Caulerpa lentillifera (Apiratikul and Pavasant, 2008), bagasse fly ash (Gupta and Ali, 2004), coir (Conrad and Hansen, 2007), Aspergillus niger (Kapoor et al. 1999), coconut shell charcoal (Babel and Kurniawan, 2004), coconut husk fibres (Tan et al. 1993), sugar beat pulp, maize cob, sugar cane bagasse (Sharma and Forster, 1994) for both lead(II) and chromium(VI). The groundnut hull has lower biosorption capacity than Ficus religiosa leaves (Qaiser et al. 2007) for lead(II), while biosorption capacity of groundnut hull was higher than Ficus religiosa leaves for chromium(VI).

\section{CONCLUDING REMARKS}

Groundnut hull was evaluated as possible biosorbent for removal of lead(II) and chromium(VI) from wastewater. The maximum biosorption capacity of lead(II) and chromium(VI) was $31.54 \pm 0.63$ and $30.21 \pm 0.74 \mathrm{mg} \mathrm{g}^{-1}$, respectively. The biosorption was dependent on $\mathrm{pH}$ and optimal $\mathrm{pH}$ for lead(II) and chromium(VI) was 5 and 2, respectively. The equilibrium and kinetics data at different temperatures was used to evaluate the thermodynamics parameters. The thermodynamics studies revealed that biosorption of chromium(VI) was endothermic, while biosorption of lead(II) was exothermic. The biosorption followed the Langmuir model. The kinetics of biosorption was well represented by pseudo second order kinetic model. The release of $\mathrm{Ca}, \mathrm{Mg}$ and $\mathrm{Na}$ and $\mathrm{K}$ ions in lead(II) biosorption and $\mathrm{OH}^{-}$ions in chromium(VI) biosorption, revealed that ion exchange was the major removal mechanism.

\section{ACKNOWLEDGEMENTS}

The authors are thankful to Mr. Umar, Mr. Zafar and Mr. Furqan for providing the analytical facilities. Special thanks are for Lt. General (R) Muhammad Akram Khan, the worthy Vice Chancellor, University of Engineering and Technology Lahore, for his encouragements and providing the facilities for this research.

\section{REFERENCES}

AMARASINGHE, B.M.W.P.K. and WILLIAMS, R.A. Tea waste as a low cost adsorbent for the removal of $\mathrm{Cu}$ and $\mathrm{Pb}$ from wastewater. Chemical Engineering Journal, January 2007, vol.132, no. 1-3, p. 299-309.

AMUDA, O.S.; GIWA, A.A. and BELLO, I.A. Removal of heavy metal from industrial wastewater using modified activated coconut shell carbon. Biochemical Engineering Journal, September 2007, vol. 36, no. 2, p. 174-181.

APIRATIKUL, Ronbanchob and PAVASANT, Prasert. Batch and column studies of biosorption of heavy metals by Caulerpa lentillifera. Bioresource Technology, May 2008, vol. 99, no. 8, p. 2766-2777.

BABARINDE, N.A.A.; BABALOLA, J.O. and SANNI, R.A. Biosorption of lead ions from aqueous solution by maize leaf. International Journal of Physical Sciences, September 2006, vol. 1, no.1, p. 23-26.

BABEL, Sandhyaand KURNIAWAN, Tonni Agustiono. $\mathrm{Cr}(\mathrm{VI})$ removal from synthetic wastewater using coconutshell charcoal and commercial activated carbon modified with oxidizing agents and/or chitosan. Chemosphere, February 2004, vol. 54, no. 7, p. 951-967.

BEKTAS, Nihal; AGIM, Burcu Akman and KARA, Serdar. Kinetic and equilibrium studies in removing lead ions from aqueous solution by natural sepiolite. Journal of Hazardous Materials, August 2004, vol. 112, no. 1-2, p. 115-122.

BHATTACHARYYA, Krishna G. and GUPTA, Susmita Sen. Adsorption of chromium(VI) from water by clays. Industrial Engineering and Chemistry Research, September 2006, vol. 45, no. 21, p. 7232-7240.

BROWN, Pauline; JEFCOAT, I. Atly; PARRISH, Dana; GILL, Sarah and GRAHAM, Elizabeth. Evaluation of the adsorptive capacity of peanut hull pellets for heavy metals in solution. Advances in Environmental Research, June 2000, vol. 4, no. 1, p. 19-29.

BULUT, Yasemin and TEZ, Zeki. Adsorption studies on ground shells of hazelnut and almond. Journal of 
Hazardous Materials, October 2007, vol. 149, no. 1, p. 3541.

CHEN, J. Paul; WANG, Lin and ZOU, Shuai-Wen. Determination of lead biosorption properties by experimental and modeling simulation study. Chemical Engineering Journal, July 2007, vol. 131, no. 1-3, p. 209215.

CONRAD, Kathrine and HANSEN, Hans Christian Bruun. Sorption of zinc and lead on coir. Bioresource Technology, January 2007, vol. 98, no. 1, p. 89-97.

CIMINO, Giuseppe; PASSERINI, Amedeo and TOSCANO, Giovanni. Removal of toxic cations and $\mathrm{Cr}(\mathrm{VI})$ from aqueous solution by hazelnut shell. Water Research, August 2000, vol. 34, no. 11, p. 2955-2962.

FREUNDLICH, H. Colloid and capillary chemistry. E.P. Dutton and Co., New York, 1928.

GUPTA, Vinod K.; MOHAN, Dinesh and SHARMA, Saurabh. Removal of lead from waste water using bagasse fly ash-A sugar industry waste material. Separation Science and Technology, 1998, vol. 33, no. 9, p. 1331-1343.

GUPTA, Vinod K. and ALI, Imran. Removal of lead and chromium from wastewater usingbagasse fly ash-a sugar industry waste. Journal of Colloid and Interface Science, March 2004, vol. 271, no. 2, p. 321-328.

HO, Yuh-Shan. Effect of $\mathrm{pH}$ on lead removal from water using tree fern as the sorbent. Bioresource Technology, July 2005, vol. 96, no. 11, p. 1292-1296.

HO, Y.S. and MCKAY, G. Pseudo-second order model for sorption processes. Process Biochemistry, July 1999, vol. 34, no. 5, p. 451-465.

KAIKAKE, Katsuya; HOAKI, Keiji; SUNADA, Hiromasa; DHAKAL, Rabindra Prasad and BABA, Yoshinari. Removal characteristics of metal ions using degreased coffee beans: Adsorption equilibrium of cadmium(II). Bioresource Technology, November 2007, vol. 98, no. 15, p. 2787-2791.

KANNAN, Nagarethinam and SUNDARAM, Mariappan Meenakshi. Kinetics and mechanism of removal of methylene blue by adsorption on various carbons-a comparative study. Dyes and Pigments, October 2001, vol. 51, no. 1, p. 25-40.

KAPOOR, A.; VIRARAGHARAN, T. and CULLIMORE, R.D. Removal of heavy metals using the fungus Aspergillus niger. Bioresource Technology, October 1999, vol. 70, no. 1, p. 95-104.

KRATOCHVIL, David and VOLESKY, Bohumil. Advances in the biosorption of heavy metals. Trends in Biotechnology, July 1998, vol. 16, no. 7, p. 291-300.
LAGERGREN, S. Zur theone der sogenannten adsorption gelostn. Stoffe. Stcok. Ak. Handl. Bihay, 1898, 24(Afd. I), p. 39.

LANGMUIR, I. The sorption of gases on plane surfaces of glass, mica and platinum. Journal of the American Chemical Society, 1918, vol. 40, 1361-1403.

MALIK, R.; RAMTEKE, D.S. and WATE, S.R. Adsorption of malachite green on groundnut shell waste based powdered activated carbon. Waste Management, 2007, vol. 27, no. 9, p. 1129-1138.

MOHANTY, K.; JHA, M.; BISWAS, M.N. and MEIKAP, B.C. Removal of chromium(VI) from dilute aqueous solutions by activated carbon developed from Terminalia arjuna nuts activated with zinc chloride. Chemical Engineering Science, June 2005, vol. 60, no. 11, p. 30493059.

MUNGASAVALLI, Deepa Prabhu; VIRARAGHAVAN, Thiruvenkatachari and JINYee-Chung. Biosorption of chromium from aqueous solutions by pretreated Aspergillus niger: Batch and column studies. Colloids and Surfaces A: Physicochemical Engineering Aspects, July 2007, vol. 301, no. 1-3, p. 214-223.

NADEEM, M.; MAHMOOD, A.; SHAHID, S.A.; SHAH, S.S.; KHALID, A.M. and MCKAY, G. Sorption of lead from aqueous solution by chemically modified carbon adsorbents. Journal of Hazardous Materials, December 2006, vol. 138, no. 3, p. 604-613.

OZER, A. Removal of $\mathrm{Pb}(\mathrm{II})$ ions from aqueous solutions by sulphuric acid-treated wheat bran. Journal of Hazardous Materials, March 2007, vol. 141, no. 3, p. 753-761.

PARK, Donghee; YUN, Yeoung-Sangand PARK, Jong Moon. Studies on hexavalent chromium biosorption by chemically treated biomass of Ecklonia sp. Chemosphere, September 2005, vol. 60, no. 10, p. 1356-1364.

QAISER, Suleman; SALEEMI, Anwar Rasheed and AHMAD, Muhammad Mahmood. Heavy metal uptake by agro based waste materials. Electronic Journal of Biotechnology, July 2007, vol. 10, no. 3, p. 409-416.

QAISER, Suleman; SALEEMI, Anwar Rasheed and UMAR, Muhammad. Biosorption of lead from aqueous solution by Ficus religiosa leaves: Batch and column study. Journal of Hazardous Materials, July 2009, vol. 166, no. 23, p. 998-1005.

SAEED, Asma, IQBAL, Muhammed and AKHTAR, M. Waheed. Removal and recovery of lead(II) from single and multimetal $(\mathrm{Cd}, \mathrm{Cu}, \mathrm{Ni}, \mathrm{Zn})$ solutions by crop milling waste (black gram husk). Journal of Hazardous Materials, January 2005, vol. 117, no. 1, p. 65-73. 
SANGI, Mohammad Reza; SHAHMORADI, Ali; ZOLGHARNEIN, Javad; AZIMI, Gholam Hassan and GHORBANDOOST, Morteza. Removal and recovery of heavy metals from aqueous solution using Ulmus carpinifolia and Fraxinus excelsior tree leaves. Journal of Hazardous Materials, July 2008, vol. 155, p. 513-522.

SENTHILKUMAR, R.; VIJAYARAGHAVAN, K.; THILAKAVATHI, M.; IYER, P.V.R. and VELAN, M. Application of seaweeds for the removal of lead from aqueous solution. Biochemical Engineering Journal, March 2007, vol. 33, no. 3, p. 211-216.

SHARMA, D.C. and FORSTER, C.F. A preliminary examination into the adsorption of hexavalent chromium using low-cost adsorbents. Bioresource Technology, June 1994, vol. 47, no. 3, p. 257-264.

TAN, W.T.; OOL, S.T. and LEE, C.K. Removal of Cr(VI) from solution by coconut husk and palm pressed fibres. Environmental Technology, March 1993, vol. 14, no. 3, p. 277-282.

VERMA, A.; CHAKRABORTY, S. and BASU, J.K. Adsorption study of hexavalent chromium using tamarind hull-based adsorbents. Separation and Purification Technology, July 2006, vol. 50, no. 3, p. 336-341.

VOLESKY, B. Sorption and biosorption. Montreal-St. Lambert, Quebec, Canada, BV Sorbex Inc., 2003. 316 p. ISBN 0-9732983-0-8.

WANG, Yuen-Hua; LIN, Su-Hsia and JUANG, Ruey-Shin. Removal of heavy metal ions from aqueous solutions using various low-cost adsorbents. Journal of Hazardous Materials, August 2003, vol. 102, no. 2, p. 291-302.

ZHANG, Yue and BANKS, Charles. A comparison of the properties of polyurethane immobilised Sphagnum moss seaweed, sunflower waste and maize for the biosorption of $\mathrm{Cu}, \mathrm{Pb}, \mathrm{Zn}$ and $\mathrm{Ni}$ in continuous flow packed columns. Water Research, February 2006, vol. 40, no. 4, p. 788-798.

ZULKALI, M.M.D.; AHMAD, A.L. and NORULAKMAL N.H. Oryza sativa L. husk as heavy metal adsorbent: Optimization with lead as model solution. Bioresource Technology, January 2006, vol. 97, no. 1, p. 21-25. 


\section{APPENDIX}

\section{FIGURES}

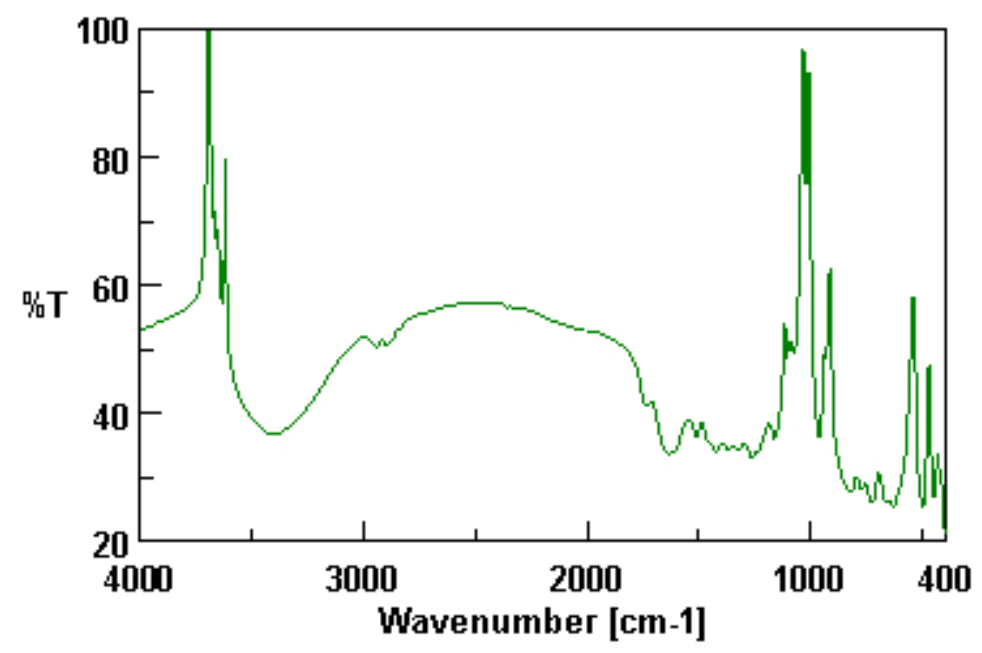

Figure 1. FTIR spectra of groundnut hull.

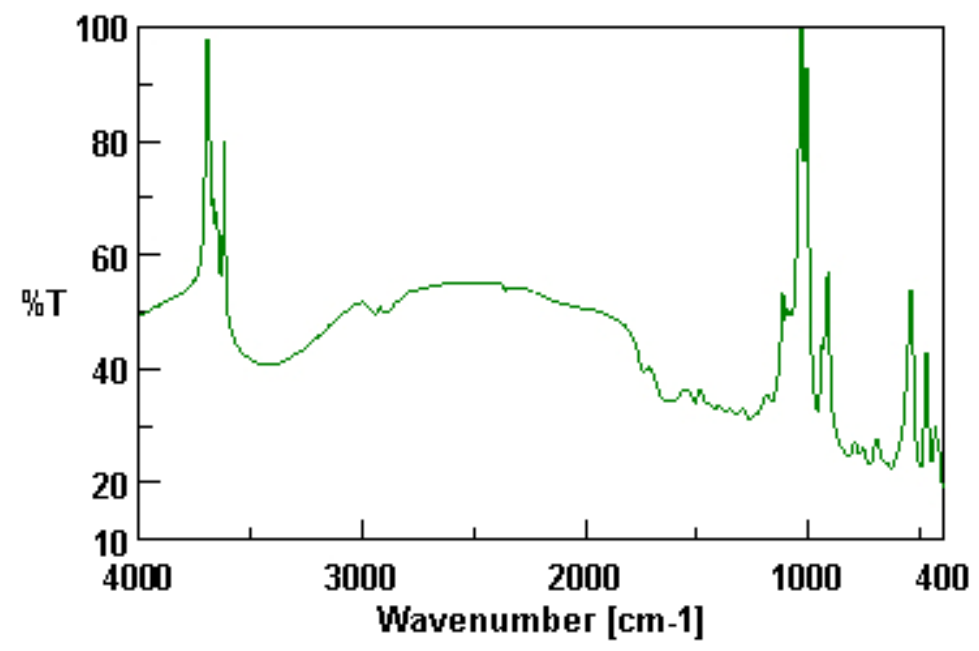

Figure 2. FTIR spectra of lead loaded groundnut hull. 


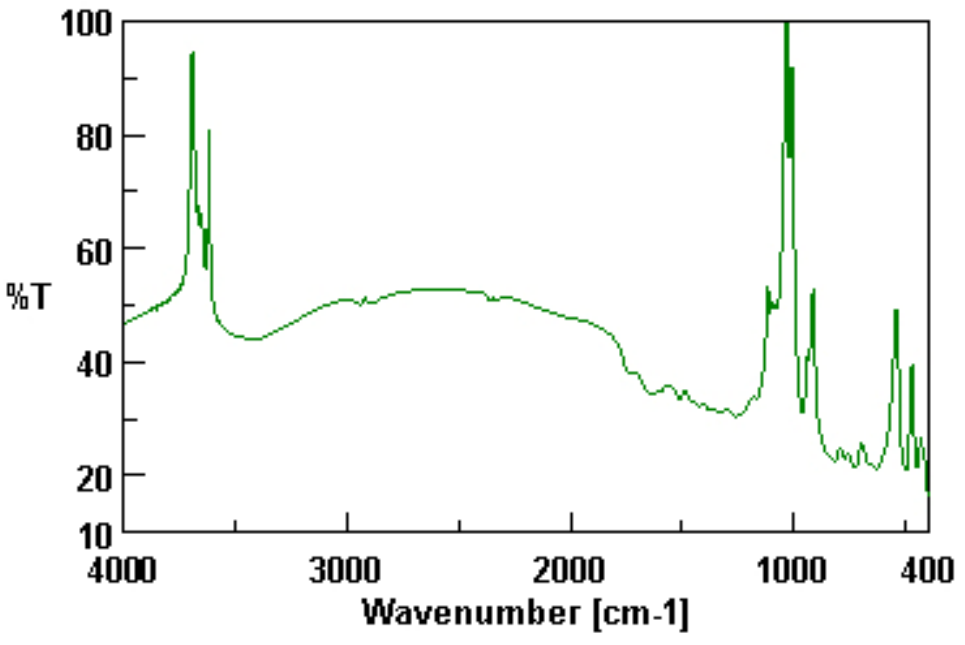

Figure 3. FTIR spectra of chromium loaded groundnut hull.
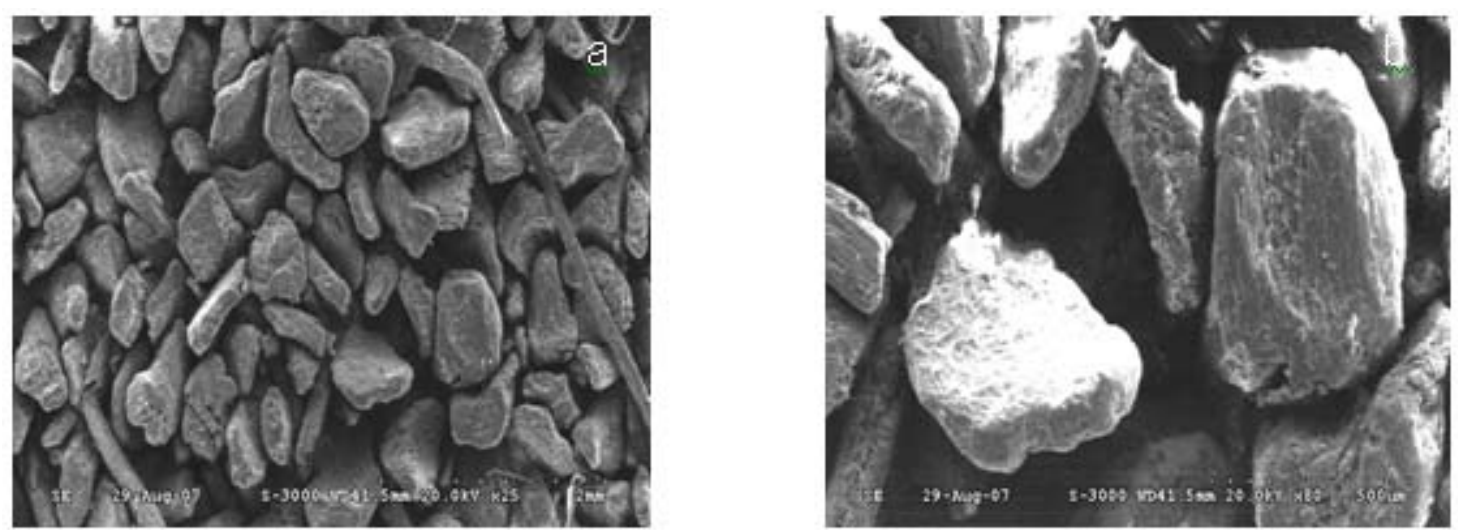

Figure 4. SEM micrographs of groundnut hull. 
Qaiser, S. et al.

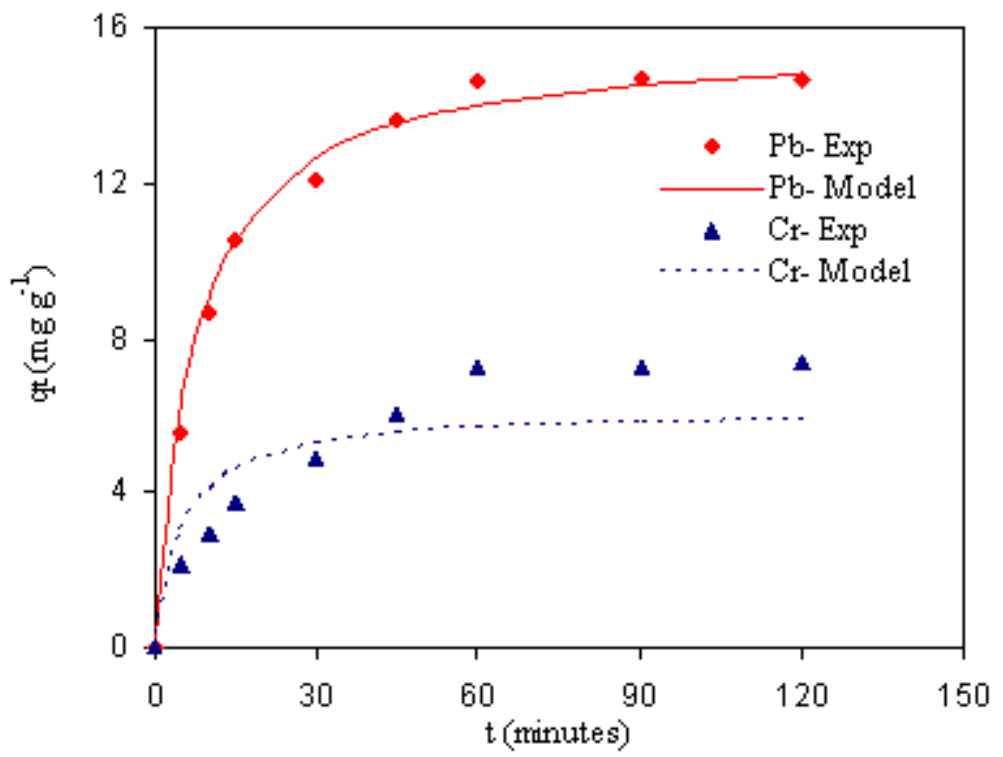

Figure 5. Equilibrium time for lead(II) and chromium(VI) biosorption. Initial concentration $=100 \mathrm{mg} \mathrm{I}^{-1}, 0.5 \mathrm{~g} \mathrm{in} 100 \mathrm{ml}, 27^{\circ} \mathrm{C}, 200 \mathrm{rpm}$, $\mathrm{pH}(\mathrm{Pb})=4.1, \mathrm{pH}(\mathrm{Cr})=2.0$.

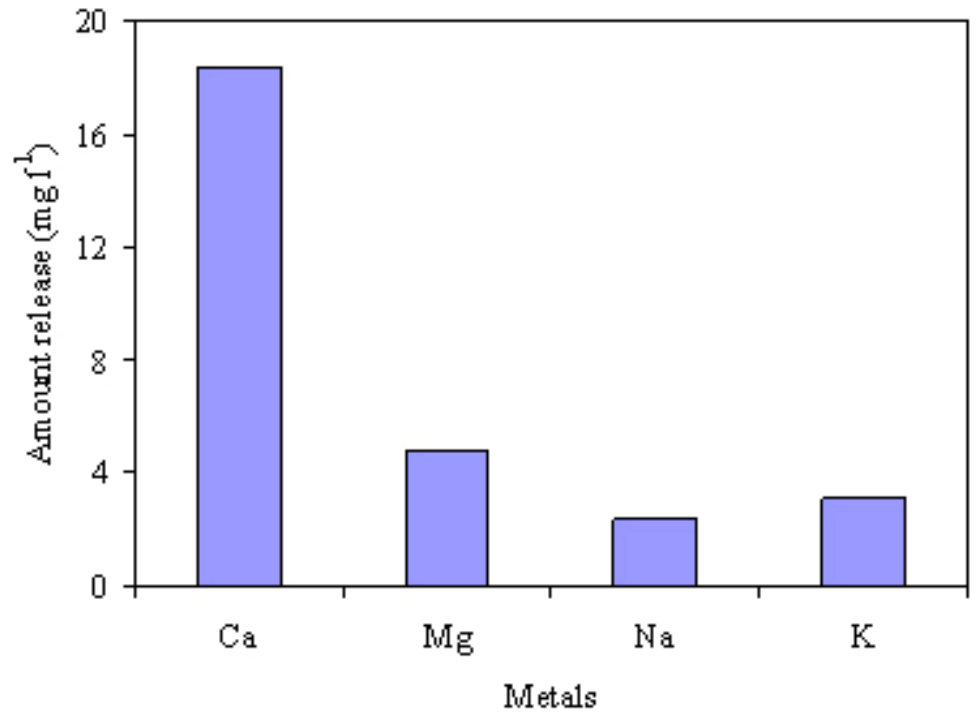

Figure 6. Release of light metals as result of lead biosorption. 


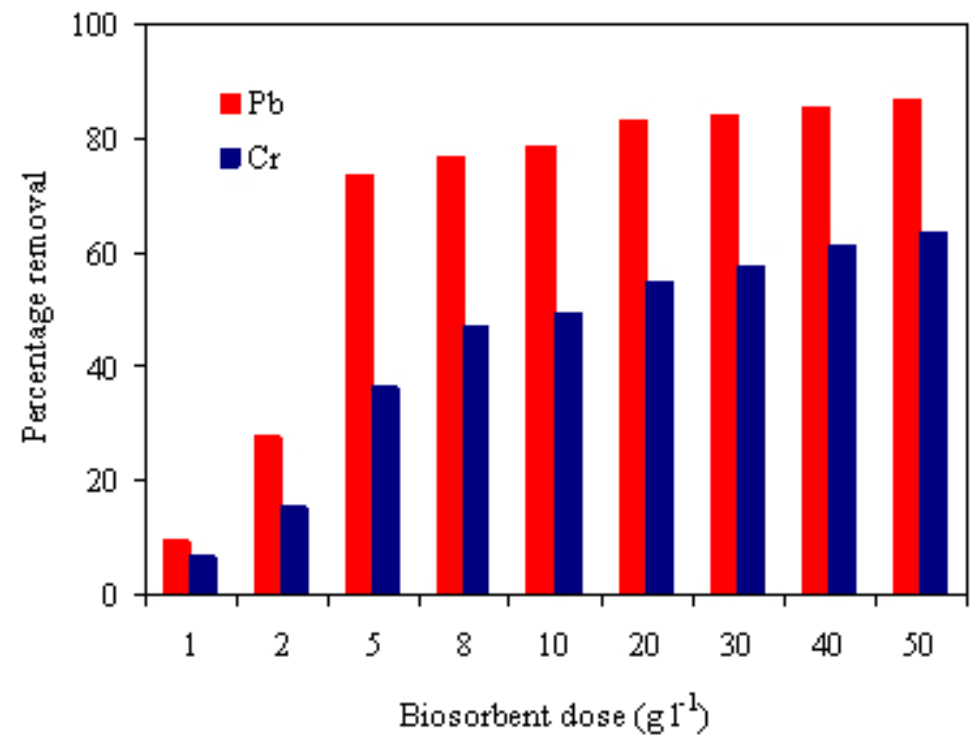

Figure 7. Optimal dose for lead(II) and chromium(VI) biosorption. Initial concentration $=100 \mathrm{mg} \mathrm{l}^{-1}, 100 \mathrm{ml}, 27^{\circ} \mathrm{C}, 200 \mathrm{rpm}, \mathrm{pH}(\mathrm{Pb})=$ $4.1, \mathrm{pH}(\mathrm{Cr})=2.1,1 \mathrm{hr}$.

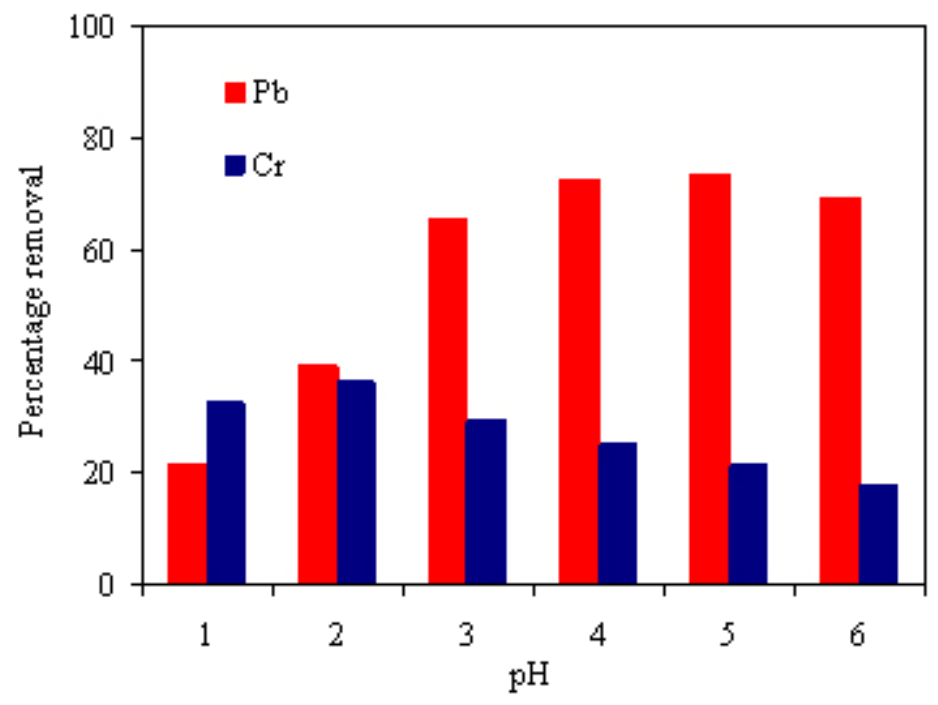

Figure 8. Optimal pH for lead(II) and chromium(VI) biosorption. Initial concentration = $100 \mathrm{mg} \mathrm{l}^{-1}, 0.5 \mathrm{~g} \mathrm{in} 100 \mathrm{ml}, 27^{\circ} \mathrm{C}, 200 \mathrm{rpm}, 1 \mathrm{hr}$. 
Qaiser, S. et al.

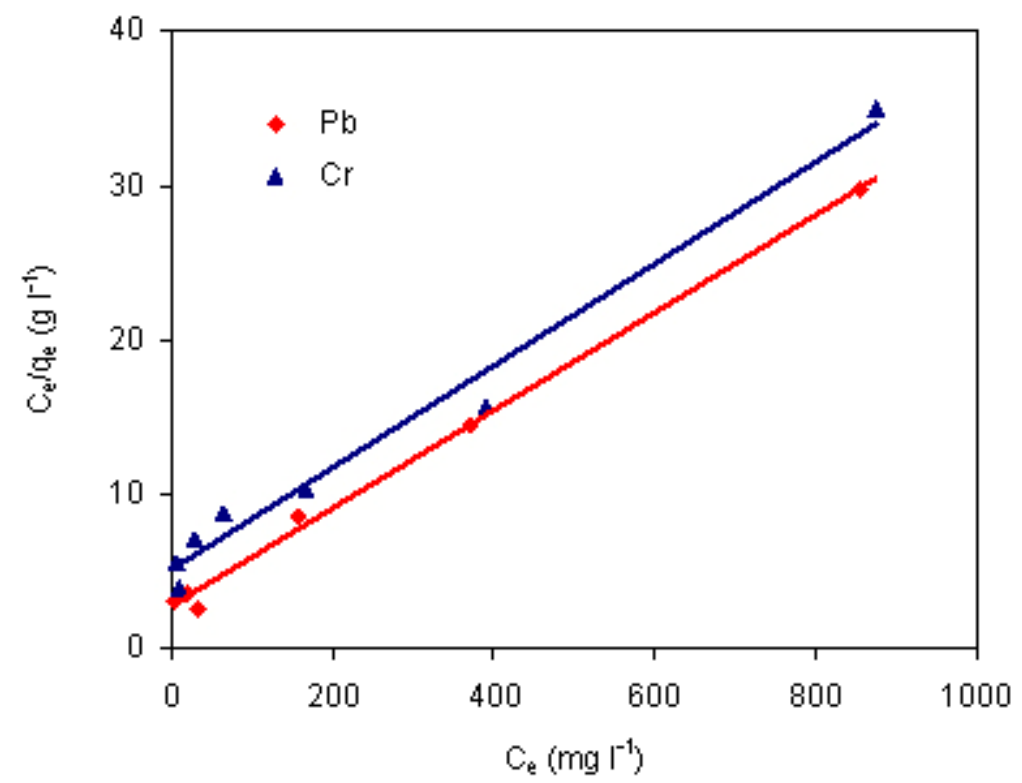

Figure 9. The Langmuir plot for lead(II) and chromium(VI) biosorption. Initial concentration $=10-1000 \mathrm{mg} \mathrm{I}^{-1}, 0.5 \mathrm{~g}$ in $100 \mathrm{ml}, 24^{\circ} \mathrm{C}$, $200 \mathrm{rpm}, \mathrm{pH}=5.1$.

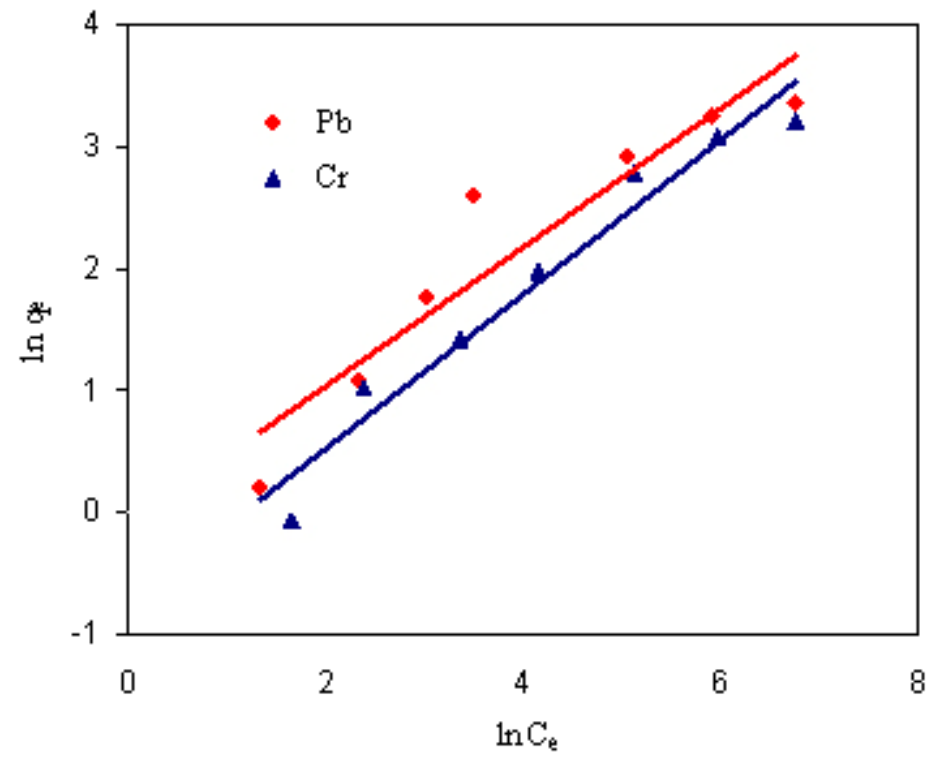

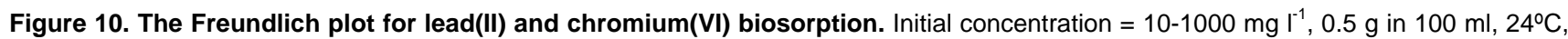
$200 \mathrm{rpm}, \mathrm{pH}=5.1$. 


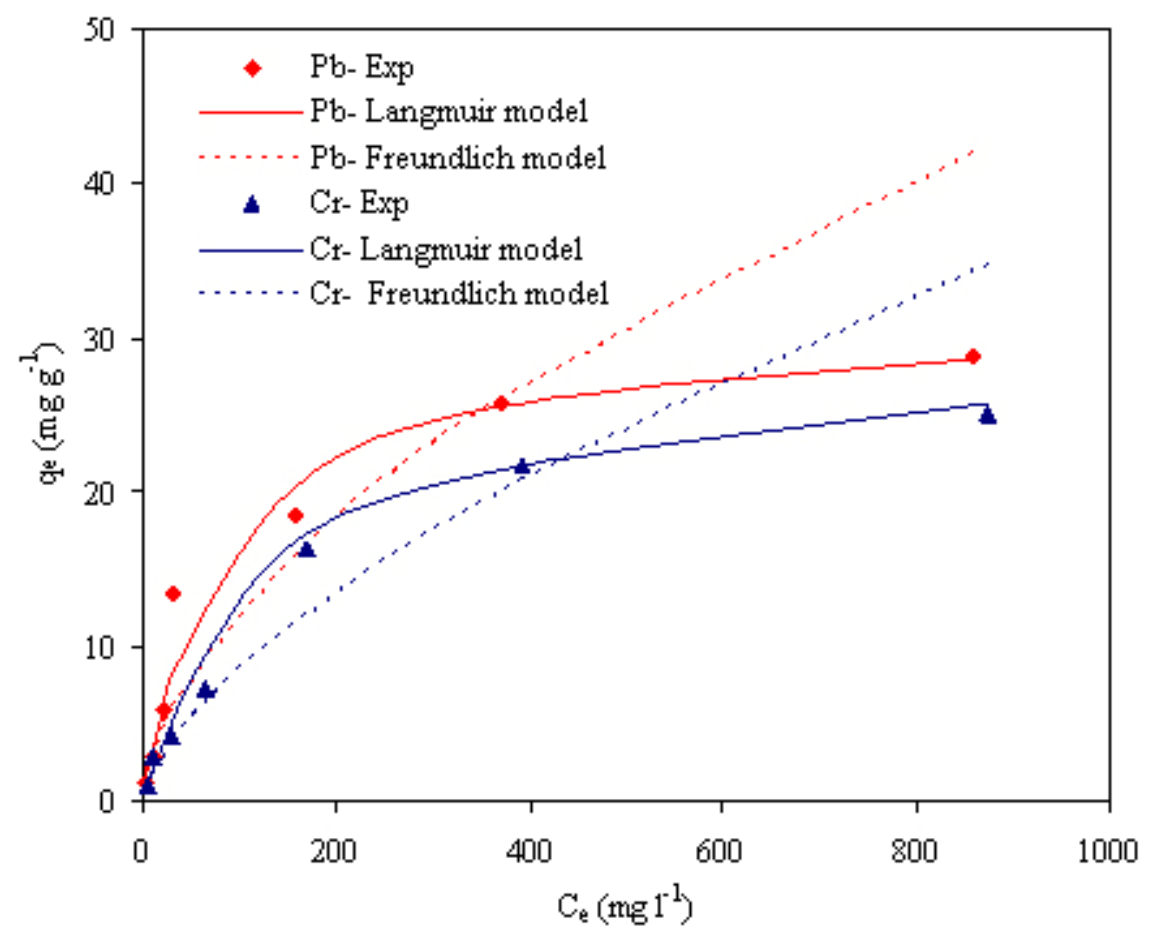

Figure 11. Experimental and theoretical equilibrium biosorption isotherms.

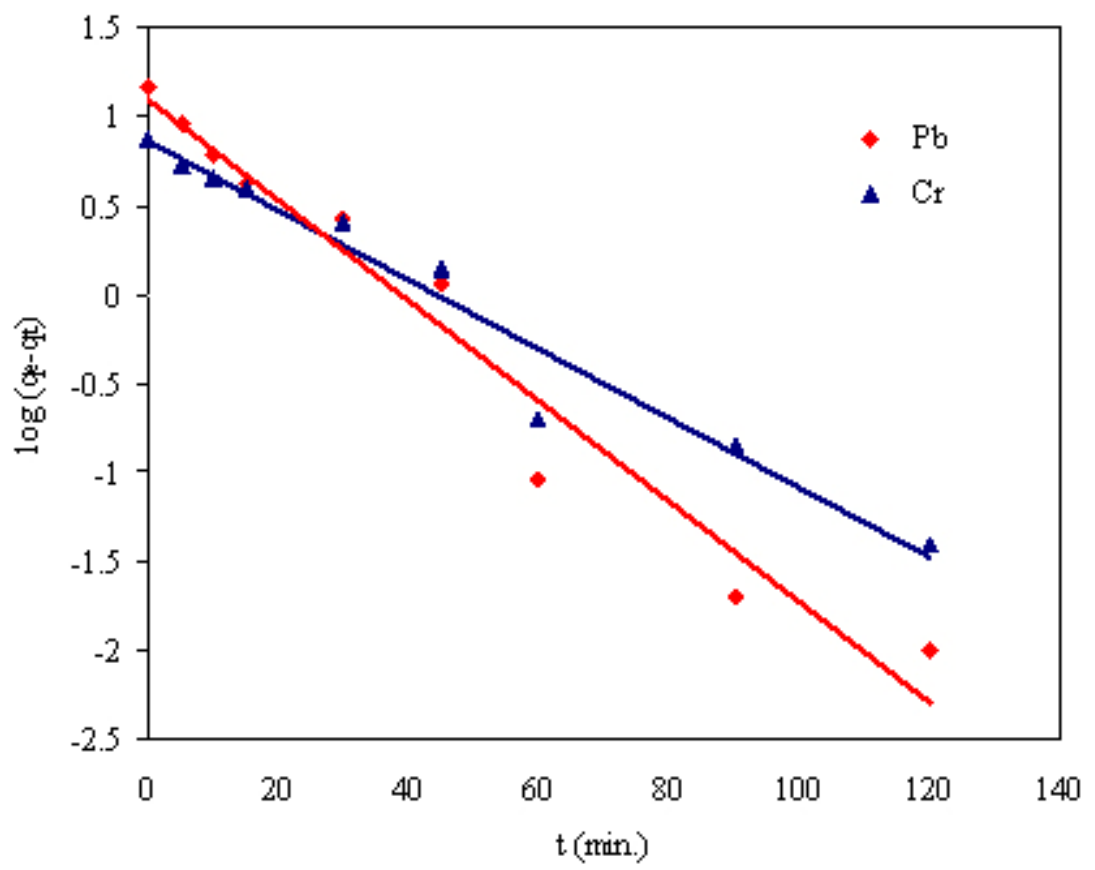

Figure 12. The Lagergren first order model plot lead(II) and chromium(VI) biosorption. Initial concentration $=100 \mathrm{mg} \mathrm{I}^{-1}, 0.5 \mathrm{~g}$ in 100 $\mathrm{ml}, 20^{\circ} \mathrm{C}, 200 \mathrm{rpm}, \mathrm{pH}=5.3,1 \mathrm{hr}$. 
Qaiser, S. et al.

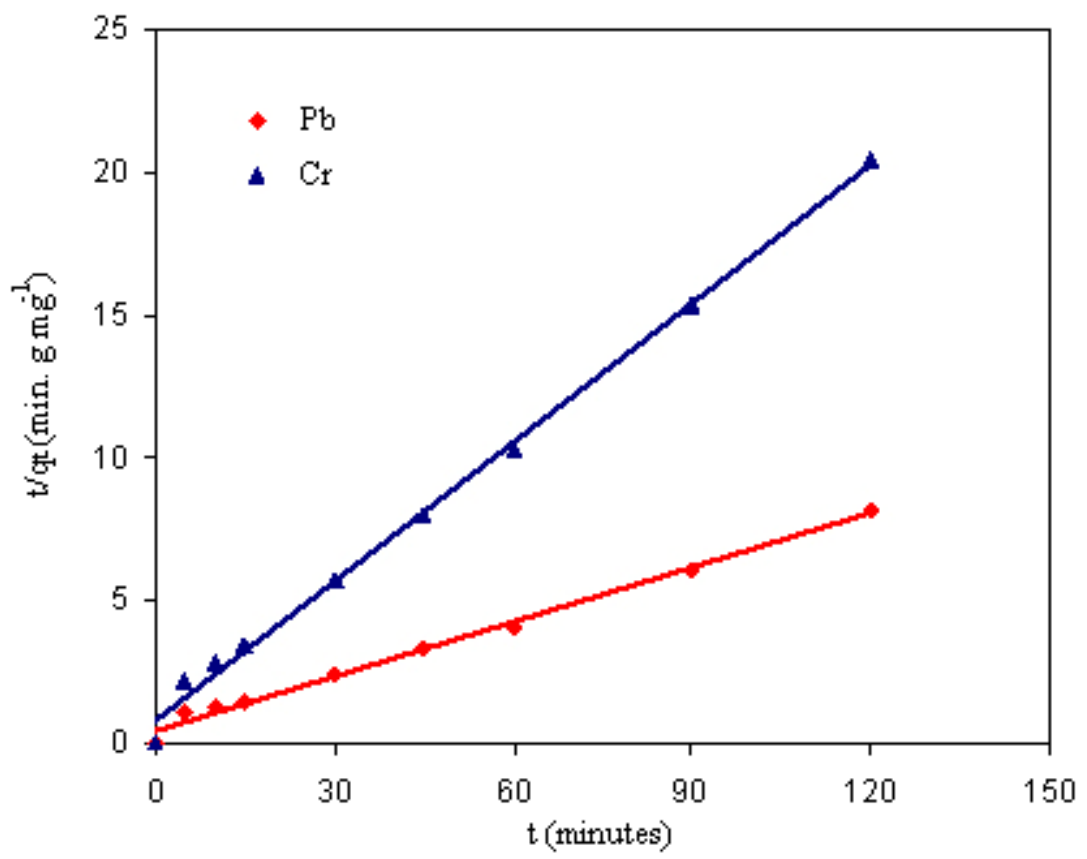

Figure 13. Pseudo second order model plot for lead(II) and chromium(VI) biosorption. Initial concentration $=100 \mathrm{mg} \mathrm{I}^{-1}, 0.5 \mathrm{~g}^{\text {in }} 100$ $\mathrm{ml}, 20^{\circ} \mathrm{C}, 200 \mathrm{rpm}, \mathrm{pH}=5.3,1 \mathrm{hr}$.

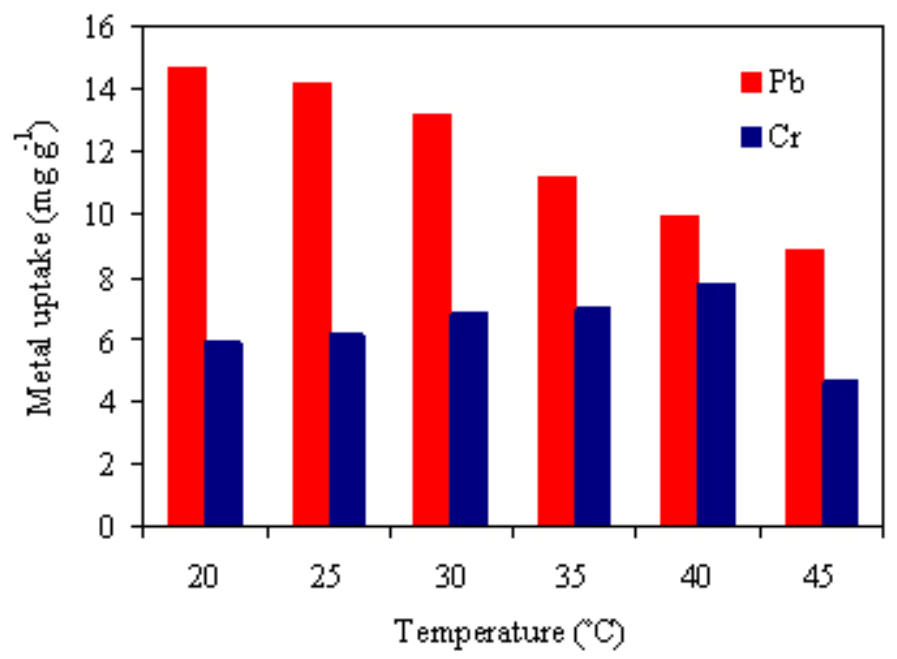

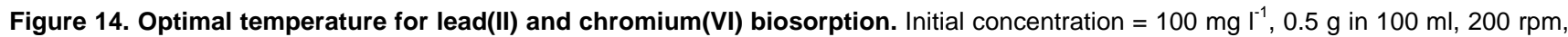
$\mathrm{pH}=5.3,1 \mathrm{hr}$. 


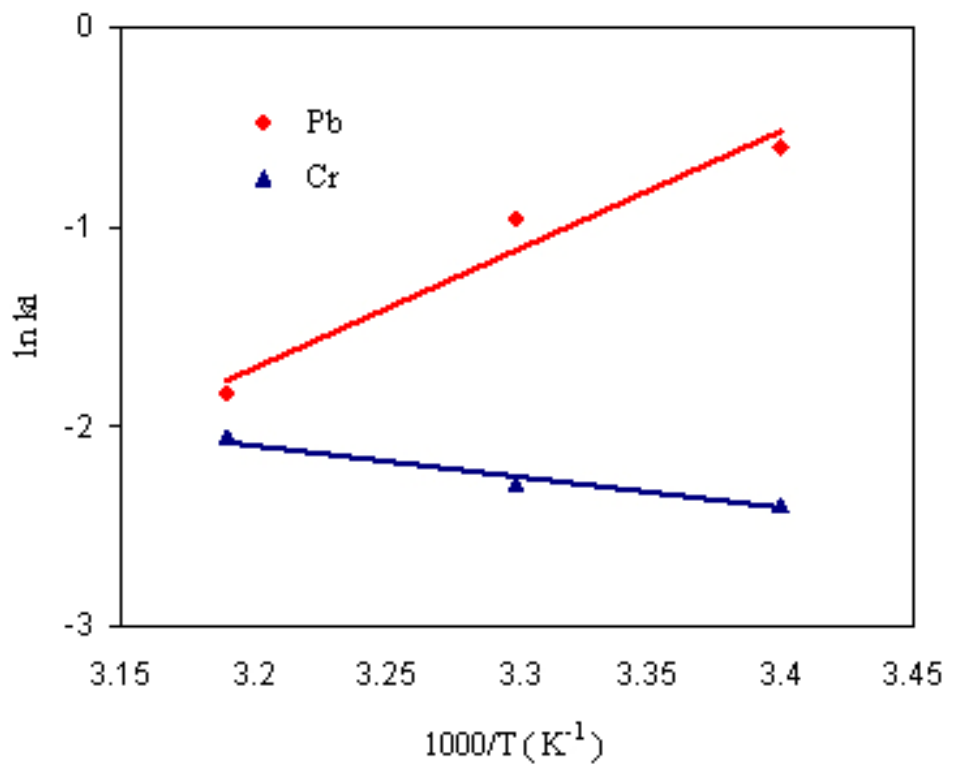

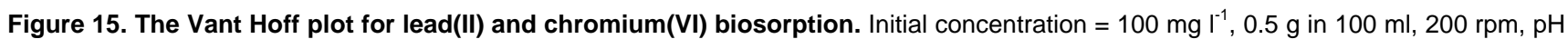
$=5.3,1 \mathrm{hr}$. 